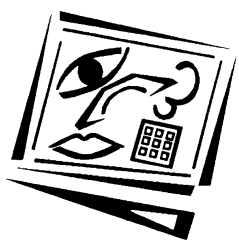

\title{
Engaging academically at risk primary school students in an ICT mediated after school program
}

\author{
Tay Lee Yong \\ Beacon Primary School, Singapore \\ Lim Cher Ping \\ Edith Cowan University
}

\begin{abstract}
This case study documents how a group of 14 academically at risk Primary 5 students (11 year olds) were engaged in academic related tasks in an after school program mediated by a 3-D Multi-User Virtual Environment (MUVE). Although there was no significant difference in the students' academic performance, they were found to be more engaged in the learning tasks and had acquired a range of information and communication technology (ICT) skills. At the start of the program students attended irregularly, but this improved gradually over the weeks, and other Primary 5 students were attracted to enrol in the program. The planned schedule of the after school program and the 3-D MUVE provided the structures and online learning environment to engage these students. This paper reports on the after school program from the perspectives of the students and teachers, emphasising its context, that is, the school setting. The main finding suggests that the role of ICT has to go beyond the role of a mediating tool. It has to entice these students to be first interested in the virtual learning environment and subsequently in the content embedded within this environment. Thus ICT becomes a means to an end as well as an end by itself, in this process of engaging students. This finding has design implications especially for the use of ICT to engage academically at risk students.
\end{abstract}

\section{Introduction}

Students' academic achievements in many countries have always been measured in terms of test scores, grades in high stakes paper and pencil tests, and other forms of assessments. Assessment is an important process in teaching and learning as it is not only a form of feedback to students, it is also a form of accountability to the other stakeholders - parents and political leaders - about the quality of the educational system. However, it is common to observe that there is a small percentage of students who constantly are not performing up to the expected standards. They often run the risk of giving up in school and worse, their own learning. This is particularly detrimental when it happens to students who are still in their elementary levels (Girod, Martineau \& Zhao, 2004; Margolis \& McCabe, 2006).

Some may argue that these students may have some forms of learning disability or difficulty. However, in the Singapore school system, students with disabilities are usually channelled to special schools and programs for further assistance. Factors such as students' motivation and their socio-economic status usually account for students' poor academic performance in the mainstream schools (see Quah, Sharpe, Lim \& Heng, 1999; and Mukhopadhaya, 2003 for Singapore Education Policy and possible 
factors affecting students' academic achievements). Although the socio-economic status of these students is beyond the control of the schools, schools have a social responsibility to reach out to these academically at risk students using new and innovative ways to engage them in learning and school related activities.

Computer and online gaming have become areas of research interest in education in recent years. The main attraction is how educators may draw upon the concepts and ideas in game design to engage learners, especially school age students. Many students spend considerable amounts of time, and perhaps money also, understanding and exploring these games. Such excitement and engagement among students playing computer games bears considerable potential for education (Gee, 2004). In contrast, learning activities in schools have not secured the engagement of all of these students. Classroom activities have increasingly been driven by the development and implementation of nationwide curricular standards and an expansion of standardised testing. Such a focus on standards, grades, and outcome measures are in direct opposition to the idea of designing learning environments that are more likely to engage the students. Learner engagement is paramount to learning success; where engagement entails mindfulness, intrinsic motivation, cognitive effort and attention (Herrington, Oliver \& Reeves, 2003).

In this paper, it is proposed that the use of a three dimensional Multi-User Virtual Environment (3-D MUVE) in an after school program may engage academically at risk students in learning tasks, especially given that the 3-D MUVE has several game like elements. These game like elements include a back story, avatars with defined roles, a reward and points system, and exploration of different worlds to accomplish tasks. This paper documents how a group of 14 academically at risk Primary 5 students (11 year olds) at Central Primary School in Singapore engaged in learning tasks. For these students, it appeared that the normal classroom setting and pedagogy had been unsuccessful in engaging them in the learning tasks. The authors sought to use the 3-D MUVE coupled with an appropriate pedagogy, namely inquiry based learning, to design an engaging learning environment. An after school setting is proposed because it is administratively not viable for these students, who are from the same level but from different classes, to meet during curricular hours. Moreover, an after school setting is less constraining both in terms of timetable scheduling and curriculum. In addition to the MUVE, other forms of technologies such as the Internet, scanners, digital cameras, and relevant software titles are also part of the program.

\section{After school programs, MUVEs, computer games and motivation}

Cole (1998) and Girod, Martineau and Zhao (2004) reported upon successful implementations of the Fifth Dimension and KLICK! after school programs respectively. Both programs are about using ICT to engage students in meaningful activities during after school hours. The students in these programs spent time voluntarily at the computer clubhouse creating web pages, surfing the Internet, chatting online, filming and editing digital movies, and playing games. In essence, students are engaged in learning meaningful skills. These reports suggest that after school programs are a good way to re-engage and motivate at risk students.

Other research studies suggest that after school programs committed to enriching young minds, boosting their confidence, and valuing school related activities is a good way to motivate academically at risk students. This is regardless of whether the focus 
of the program is academic performance, bonding towards school and usage of technologies in a community setting, or within a school environment (Beck, 1999; Copper, Valentine, Nye \& Lindsay, 1999; Cosden, Morrison, Gutierrez \& Brown, 2004).

Dede, Clarke, Ketelhut, Nelson and Bowman (2005) observed that research studies have been exploring the rich types of learning that take place in online game environments. However, the content acquired typically is neither related to national standards for academic content nor useful when applied to a real world context. They designed and studied a MUVE named River City for students who are struggling in school. According to them, these students are often characterised by high absentee rates, behaviour problems, low interest in science, and low self efficacy in science. The River City MUVE is designed to engage these students and support them in learning deep content and higher order skills. Their research findings have been positive as reflected in both their quantitative and qualitative data. Chee (2006) also reports positive findings on the use of interactive intelligent embodied agents within the $C$ VISions (Collaborative Virtual Interactive Simulations) virtual learning environment for students to learn Newtonian physics. The findings on the quantitative assessment of the students indicate that students either improved or maintained their initial test scores after learning in the C-VISions environment. For the qualitative findings, positive collaborative learning processes and outcomes are also reported.

Literature reviews on the use of computer games in education suggest that these games could be used to enhance and facilitate learning amongst students (Jenkins, Klopfer, Squire \& Tan, 2003). Computer games create environments that stimulate learners to become immersed in a fantasy world, motivating and engaging them in activities (Malone \& Lepper, 1987). There are also various studies that look into how computer games design can be applied in the learning of content areas in the classrooms (Amory, Naicker, Vincent \& Adams, 1999; Dickey, 2005; Gee, 2003). Amory, Naicker, Vincent and Adams (1999) proposed that skills such as logic, memory, visualisation and problem solving are critical in the playing of games. The development of these skills is fundamental to all aspects of learning. According to the authors, educational games contain different aspects - those that promote educational objectives (abstract) and those that allow for the realisation of these objectives (concrete). The authors observed that the visualisation space, problems components, story line, memory, and logic interfaces are the most important game elements for providing sufficient stimulation to engage learners in knowledge discovery, while at the same time developing new skills. In addition, Gee (2003) suggested thirty-six learning principles from good video games (video and computer games) that can be applied in the learning of content areas in the classrooms. Dickey (2005) also observed that aspects of game design fit into existing models of engaged learning and provide a fuller framework and method for integrating engagement strategies for both traditional education media and interactive learning environments. The engagement strategies are: (1) focused goals, (2) challenging tasks, (3) clear and compelling standards, (4) protection from adverse consequences for initial failures, (5) affirmation of performance, (6) affiliation with others, (7) novelty and variety, and (8) choice.

Research studies on engagement advocate the importance of positive learning environments and students' motivation (Maehr \& Anderman, 1993; Roeser, Strobel \& Quihuis, 2002; Urdan, Midgley \& Anderman, 1998, Seifert \& O'Keefe, 2001). Learning environments that are nurturing and supportive develop students' sense of confidence and self determination, which may transform them into intrinsically motivated 
students who are more likely to engage in learning activities (Seifert \& O'Keefe, 2001). The Quest Atlantis Multi-User Virtual Environment seeks to create such a learning environment to better engage young learners.

\section{Quest Atlantis: A multi-user virtual environment}

Quest Atlantis $(Q A)$ is a 3-D virtual learning environment developed by the Centre for Research on Learning and Technology (CRLT) at Indiana University. The Centre is committed to exploring and developing appropriate applications of ICT to improve teaching and learning in diverse settings. This environment is built for students with ages from 8 to 12 years, who have given up on themselves as learners. It is the belief of CRLT that $Q A$ with its deep content and challenging, game like activities will motivate these academically at risk students. Figure 1 is a screen capture of the $Q A$ interface. Students explore and move around freely in the 3-D virtual world as questers with their own avatars. There is also an online synchronous chat for students to discuss topics of interest and collaborative works. On the right hand side of this environment, students can access their emails, forums, view their accumulated points and lumins, quests, as well as update their personal information.

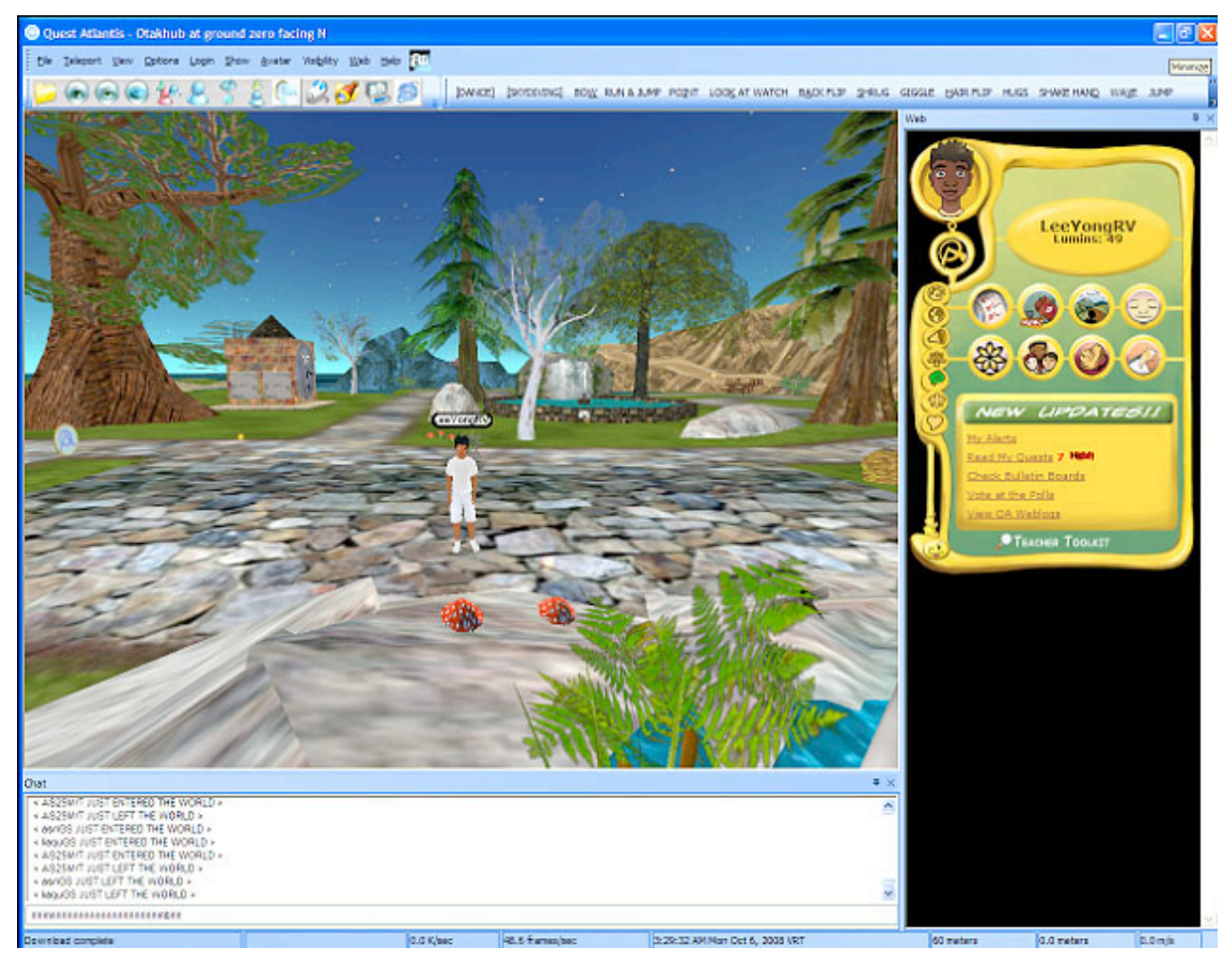

Figure 1: Screen picture of the Quest Atlantis multi-user virtual environment

$Q A$ allows students to travel to various virtual spaces and carry out educational activities known as quests. Each quest is a curricular task designed to be entertaining and yet educational in nature. In order to complete these quests, students have to 
complete real world activities that are socially and academically meaningful. All quests involve both content area findings and personal reflection by the student. This is done with the aim of fostering critical thinking and meta-cognition. Figure 2 is a screen picture illustrating a mathematics quest that requires students to complete two fractions puzzles. Students need to utilise the concepts, knowledge, and skills with fractions to solve the puzzles. After solving, the students retrieve the codes and submit them to the Atlantian Council. The teacher plays the role of an Atlantian Council member and mentor who assigns the appropriate quests to the students. Each completed quest is then submitted to the teacher (or the Council member) for review and feedback. Points (in terms of cols and lumins as known in $Q A$ ) will be rewarded for each completed quest or task. The achievements of the students are shown on their individual virtual homepages and digital portfolios.

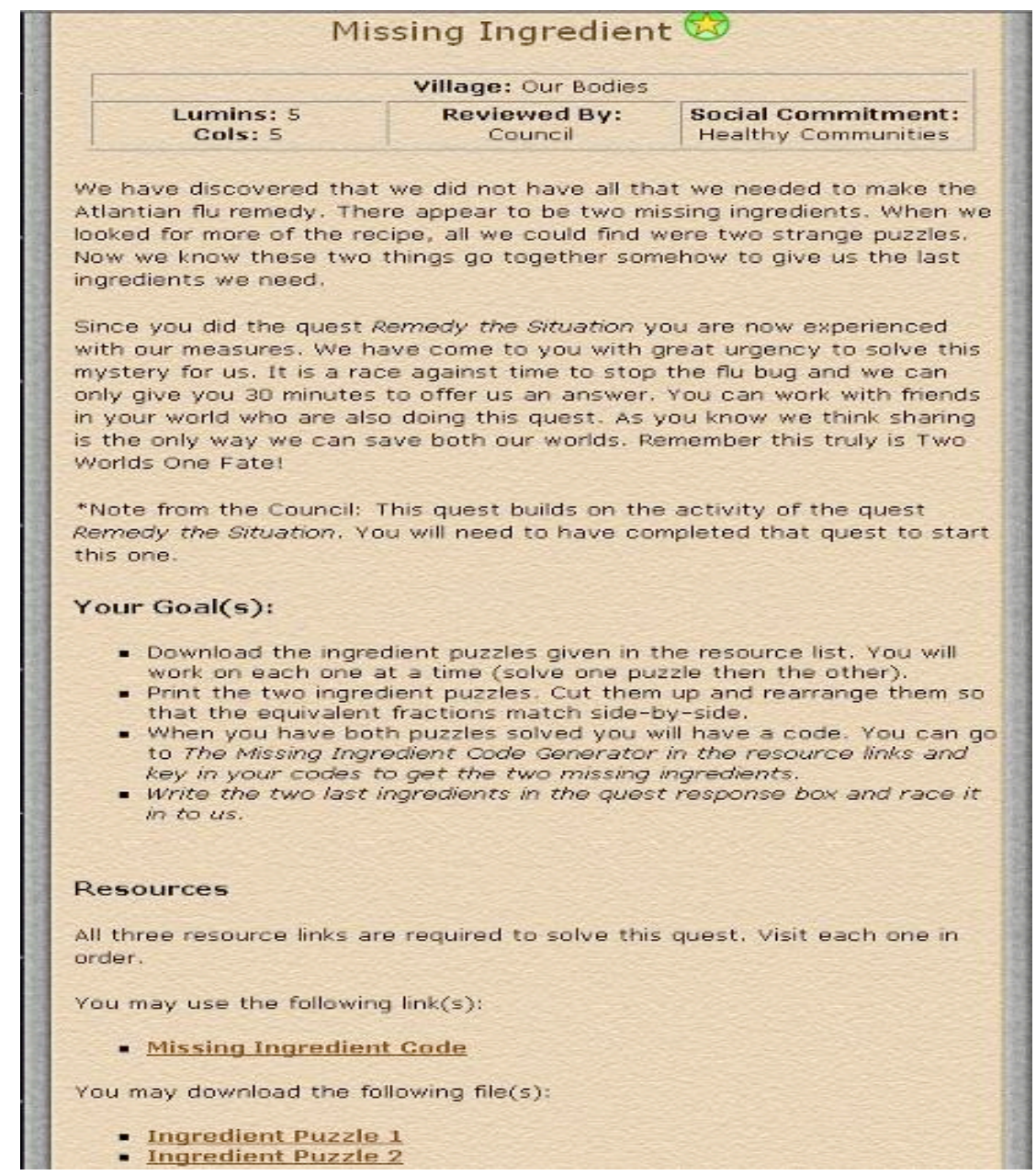

Figure 2: Screen picture of a Quest on Missing Ingredient

The context of $Q A$ is set during the orientation phase. Students are acquainted with the back story of $Q A$ - Atlantis is facing a looming disaster as a result of lost values and dishonest leadership. For the rebuilding and restoration of the lost wisdom, the 
Atlantian Council has created a series of quests for students to work on as questers. In addition, the OTAK is created for communication between Atlantis and Earth. It is through the OTAK that students participate and share their knowledge with the Atlantians on how to save and revitalise Atlantis. Students are able to interact with the digital artefacts in the virtual environment. They have their own personalised avatars or virtual characters with whom they meet and interact virtually in the various worlds. Currently, there are 11 worlds in $Q A$ and a couple more under construction and on trial. Each world has three villages that address different aspects of the world's theme, and this is done through the 20 to 25 quests encountered in each village. The quests found within this environment require students to be engaged in inquiry based learning.

\section{Inquiry based learning and Quest Atlantis}

Developers of $Q A$ believe that students learn best when they are actively engaged in the learning process, with an emphasis on inquiring into domain related problems. The basic philosophy of inquiry based learning is to make learning more meaningful, more transferable to various situations out of a specific context, and more conducive to self directed lifelong learning (Lim, Nonis \& Hedberg, 2006). NWREL (1997) suggests that in practice, inquiry often occurs on a continuum. On one end of the continuum of inquiry may be the use of highly structured hands on activities and experiments; in the middle may be guided inquiry or the use of science kits; and at the furthest end, students may be generating their own questions and investigations. The approach used in this study is towards a more structured, hands on type, taking into consideration the teacher's teaching skills, student readiness, maturity, and ability, and pedagogical goals. It is, however, the aim of this study to eventually move towards the furthest end of the continuum of inquiry.

\section{Background to the research}

This study is a part of a larger research project on games study commissioned by the Centre for Research in Practice and Pedagogy at the National Institution of Education in Singapore. It builds on earlier research studies on the implementation of $Q A$ in the United States (Barab, Thomas, Dodge, Carteaux \& Tuzun, 2005) and Singapore (Lim, Nonis \& Hedberg, 2006). The main outcome of these works is the building of a socially responsive online environment and context that is academically valuable, game like, and engaging to students of both genders.

$Q A$ was first introduced to Central Primary School in early 2003 and involved two classes of Primary 3 students (9 year olds). Initially, two classes of Primary 3 students explored $Q A$ with the first author of this paper as their teacher in one of their Science topics - human body. The quests assigned to the students were on the human eyes. With the feedback from this initial experiment, $Q A$ was later used in 2004 for a collaborative social studies project with another primary school in Singapore. The focus of these two projects was on the technical and communication aspects of the online learning environment. With the experience gained from these earlier explorations, it was decided by the authors to integrate $Q A$ into the curriculum in 2005; that is, quests were created based on the local standards and content for the Primary 5 English, Mathematics and Science Curriculum.

The earlier experiences and insights suggested that a 3-D MUVE in which students have control over their avatars could be used to motivate them. In addition, students 
are quite fascinated when they have the opportunities to experiment with and use computer related tools. However, the educational impact of simply embedding these tasks and activities within the MUVE may be limited. There may be a need to design tasks and activities that involve students in multi-modal outputs with the use of computer tools. There is also a need to look into the quality of the assignments (quests) submitted by the students to make sure that they meet curricular standards. Social and motivational factors such as the use of challenges, curiosity, control, fantasy, competition, cooperation, and recognition are also taken into account in the design and selection of tasks and activities for the students.

The objective of this study centred on how a MUVE could be used to motivate a group of academically at risk primary students within a school setting. The study was conducted from February to October 2006 with a group of 14 students who were enrolled in an after school program (within the school, but after the official curriculum time) that was conducted twice a week. The teachers negotiated with the school management for the after school program to become part of its remediation and supplementary program. Both Tuesday and Thursday afternoons from $1.30 \mathrm{pm}$ to 3.30 pm were set aside for the remediation and supplementary program; school hours were $7.30 \mathrm{am}$ to $1.00 \mathrm{pm}$. Mondays, Wednesdays and Fridays were days when the students were involved in co-curricular activities such as games and sports, clubs and societies, and uniformed groups.

\section{Research methods}

The research methods for this study included the following:

1. Reflections on the after school program from the teacher-researcher (the teacherresearcher is also the first author of this article) - Reflection notes on the after school program conducted were audio recorded and subsequently transcribed using a digital audio recorder for further analysis.

2. Meetings with teachers and researchers who were involved in this research study were also conducted to monitor the progress and triangulate the findings and observations.

3. Interview with students - Informal interview sessions were conducted to capture the voices and perception of the students. These interviews were also audio recorded and transcribed subsequently for analysis purposes.

4. Attendance of the students - The attendance of the students was recorded both as a method for tracking the students' turn out as well as an indication of their willingness and motivation to come for this after school program.

5. Students' performance in the QA MUVE - Performance indicators such as the number of quests completed, number of lumins achieved, number of cols collected, number of items collected in the their Q-pack, and number of logins to the 3-D $M U V E$ were captured for analysis and correlations.

\section{Data analysis}

In this case study, data analysis for each method was undertaken concurrently with data collection and data processing. Ongoing analyses helped to remove biases and errors that had crept into the fieldwork and to fine tune the research methods to reflect a better understanding of the setting. The data collected was continually subjected to cross checking with the various other sources of data. From the various sources of 
data, units of information were identified. These units became the basis for a more in depth understanding, appreciation, and response to the research questions drawn up for this case study.

\section{Key findings and discussion}

This research investigated both the students' motivation to attend the after school program as well as their engagement with the quests assigned to them. Attendance rate was used as an indicator of student motivation, being a good indication as students could always choose not to attend any program that was conducted after the official school hours. Engagement with the quests was determined from the students' activities during the after school program and within the $Q A M U V E$. Often students were engaged with a variety of activities other than the completion of quests. In addition, the students' academic performance is also presented and discussed.

\section{Motivation of students to the after school program}

Attendance rate improved gradually over the year long after school program. The program had also attracted other students from the same level to volunteer for it. This demonstrated the potential for the virtual environment to motivate unwilling learners to be more interested in academic related tasks. The students were very interested with the program, especially the use of the $Q A M U V E$, even after the after school program had officially ended for the year. Many of the students requested the teachers to continue the program during the end of year school holidays.

The attendance rate of the students was not satisfactory, especially during the initial phase of the implementation with only $74 \%$ attending the after school session in Term One. Teachers who conducted the after school program were also disturbed and concerned about the poor attendance. With constant reminders from the teachers, the attendance rate improved gradually as shown in Figure 3. A total of 14 students took part in the program; 9 boys and 5 girls.

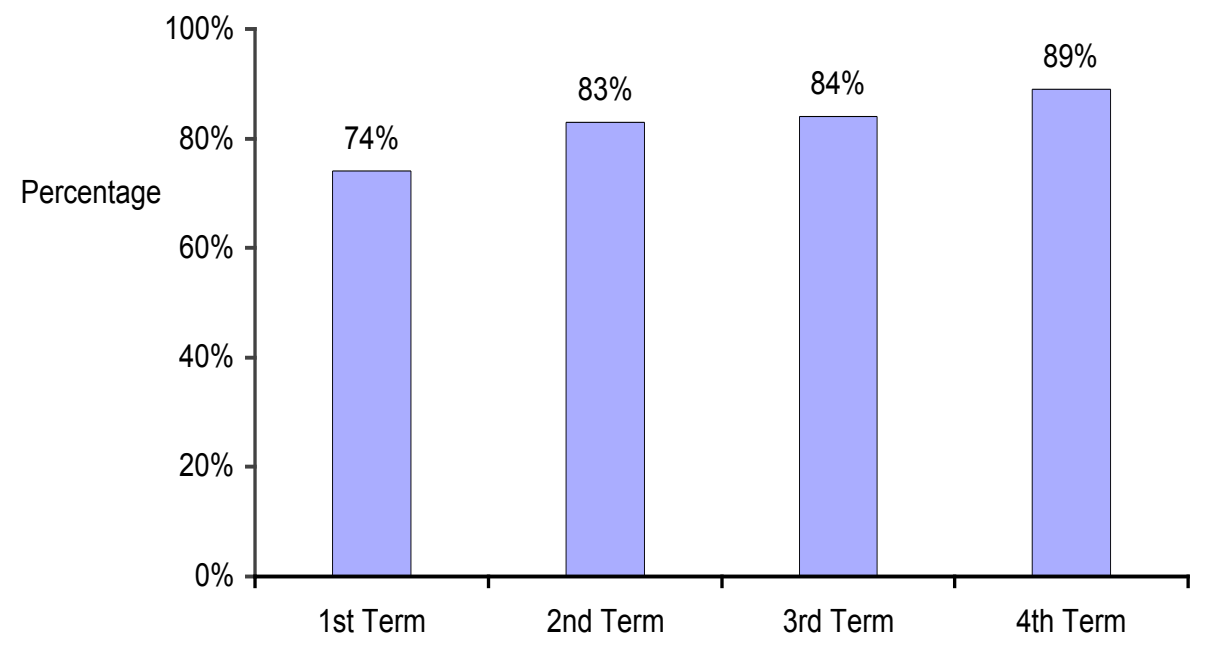

Figure 3: Attendance rate of students in the QA after school program $(n=14)$ 
The behaviour of the students in terms of their attendance at the after-school program suggested that time was needed for these students to be interested in the program. The students' behaviour changed from being unwilling participants at the beginning to 'promoters' of the QA MUVE. Through spreading the words among their classmates and peers, a number of the other students from the same level (i.e., primary 5 students) sought permission to join the after-school program in the third term. The students' level of motivation for the program was progressive. Initially, constant reminders had to be given to them to ensure that they turned up for the sessions. Even with repeated reminders, the attendance rate for Term 1 was rather worrying. Although students who were absent were questioned by the teachers, most of the time they could not give any good excuses. Most of their excuses were either commitments at home or they had forgotten to attend the after-school program.

The above discussion highlighted the importance of the teacher's role in facilitating the implementation of the after-school program, especially during the initial phases of the program to introduce such a program to this group of students. The expectation of the teachers who were conducting the program had considerable bearings on the behaviour of the students. Although many of the academically at-risk students were unwilling to attend the after-school program, a considerable number of them were still present as they knew the expectations of the teachers as well as the school where they were situated. Nevertheless, students were also attracted to the 3-D space, digital artefacts, lumins, cols, and avatars within the QA MUVE.

\section{Engagement of students with Quests}

Students' engagement with quests was basically facilitated by the teacher as the students were not intrinsically attracted to the quests. Instead, they were more interested with the 3-D space, digital artefacts, lumins, cols, and avatars within the $Q A$ $M U V E$. They were also very interested in other Internet websites such as online games and blogs. However, students were observed to have acquired useful ICT skills, such as keyboarding, the use of the Internet to search for academic related information, word processing, and presentation software. Students were also reported to be more confident and presented their experience using the QA MUVE to the Chairman of the National Research Foundation (Singapore) during the period of the project.

Table 1: Number of logins, lumins, cols and items in Q-pack

\begin{tabular}{|c|l|c|c|c|c|}
\hline S/N & $\begin{array}{c}\text { Name } \\
\text { (pseudonyms) }\end{array}$ & Logins & Lumins & Cols & $\begin{array}{c}\text { Items in } \\
\text { Q-pack }\end{array}$ \\
\hline 1 & Jo & 65 & 6 & 25 & 5 \\
\hline 2 & Bernadette & 62 & 20 & 55 & 9 \\
\hline 3 & Zhang & 68 & 7 & 37 & 32 \\
\hline 4 & Carl & 131 & 26 & 58 & 48 \\
\hline 5 & Hillary & 142 & 18 & 40 & 68 \\
\hline 6 & Yin & 273 & 20 & 107 & 71 \\
\hline 7 & Simon & 150 & 14 & 45 & 56 \\
\hline 8 & Sheng & 123 & 13 & 29 & 19 \\
\hline 9 & Cherry & 68 & 2 & 7 & 16 \\
\hline 10 & Yeng & 84 & 2 & 18 & 26 \\
\hline 11 & Hong & 104 & 4 & 31 & 51 \\
\hline 12 & Weng & 109 & 14 & 35 & 25 \\
\hline 13 & Paul & 111 & 2 & 14 & 39 \\
\hline 14 & Ken & 85 & 2 & 0 & 31 \\
\hline \multicolumn{2}{|l|}{ Means } & 112.5 & 10.7 & 35.8 & 35.4 \\
\hline
\end{tabular}


This group of students was not intrinsically attracted to the quests that were assigned to them. Of the 19 quests made available by the teachers, the students attempted an average of 9.6 quests. The students' average acceptance rate was 4.6 for the quests. Students had to be guided and reminded on their attempts at the quests. The students however reflected that they liked the 3-D space, lumins, cols, avatars, and digital artefacts found within the QAMUVE. They were also found to be engaged in exploration and playing online games and visiting blogs. Table 1 presents the total number of logins, lumins, cols, and items in Q-packs earned by the students in the after school program. Table 2 presents the correlations of these items mentioned in Table 1.

Table 2 shows the Pearson's correlations of the number of logins, lumins and cols earned by the students, and the number of items collected in their Q-packs by the 14 students since the beginning of the year.

Table 2: Correlations of logins, lumins, cols and items in Q-pack $(\mathrm{N}=14)$

\begin{tabular}{|l|l|c|c|c|c|}
\hline \multicolumn{2}{|c|}{} & Logins & Lumins & Cols & Q-pack \\
\hline \multirow{2}{*}{ Logins } & Pearson correlation & 1 & $.514^{*}$ & $.774^{* *}$ & $.781^{* *}$ \\
\cline { 2 - 6 } & Significance (1-tailed) & & .030 & .001 & .000 \\
\hline \multirow{2}{*}{ Cols } & Pearson correlation & $.514^{*}$ & 1 & $.783^{* *}$ & .370 \\
\cline { 2 - 6 } & Significance (1-tailed) & .030 & & .000 & .097 \\
\cline { 2 - 6 } & Pearson correlation & $.774^{* *}$ & $.783^{* *}$ & 1 & $.530^{*}$ \\
\cline { 2 - 6 } & Significance (1-tailed) & .001 & .000 & .026 \\
\cline { 2 - 6 } & Pearson correlation & $.781^{* *}$ & .370 & $.530^{*}$ & 1 \\
\cline { 2 - 6 } & Significance (1-tailed) & .000 & .097 & .026 & \\
\hline
\end{tabular}

${ }^{*}$ Correlation is significant at the 0.05 level (1-tailed).

** Correlation is significant at the 0.01 level (1-tailed).

The data in Table 2 shows that there was no correlation between the number of lumins received and the number of digital artefacts they collected. This non-correlation suggested that students who were more engaged with the completion of quests managed to earn more lumins but spent relatively less time exploring and hence collecting lesser digital artefacts from the 3-D virtual environment. However, it was interesting to note that although all the students were constantly reminded by the teachers to attempt and complete their quests, many of them still found ways to be engaged mainly in the collection of digital artefacts while they were exploring the 3-D space.

Interviews with the students confirmed that they spent considerable amount of time in the 3-D space, collecting digital artefacts while they were exploring it. One of the students, Yeng reflected that he liked one of the virtual worlds within the QA MUVE. "I like the QVille. I can play with airplane, car, and boat," shared Yeng. He added that he liked playing hide and seek with the boats in the 3-D space. Another student, Weng also expressed his liking for the 3-D space. "...the 3-D world is very fun." He would like to play with the online games and the cars in QVille. Paul also echoed during the interview that the 3-D space was interesting. He also liked to visit the QVille to play with the airplanes and other animated objects. Students who volunteered for the after school program during the second semester, also shared similar thoughts.

The girls also echoed similar thoughts. For Bernadette, when asked which part of the $Q A$ after-school program she liked the most, she answered that it was the 3-D space. "Walk around, play, and chat with friends. After we finished our quests, we can play hide and seek in the QA." She also tried to play with the boats in the 3-D space. For 
Hillary, she said that she would like to have more interactive elements and games in the $Q A$ MUVE when she was interviewed. "... it is quite boring and there is nothing much to do except walking around and talking. If there are more games, it will be good."

Lumins was one of the favourites amongst the students. Lumins were awarded with each successful acceptance of the quest. When a student collected enough lumins, one of his or her shard flower's petals would luminate (brighten up) as shown in Figure 4. Other than that, the student's avatar would also change from the normal avatar as shown in Figure 5a to one with a luminated shard flower on the shoulder as shown in Figure 5b. Many students, including Yin, Carl, Bernadette, Simon, Hong, Sheng, Ken, and Paul shared that they were interested in getting more lumins. The students' main purpose was to collect enough lumins so that their shard flower would luminate. In addition, they could obtain a different appearance for their avatars.

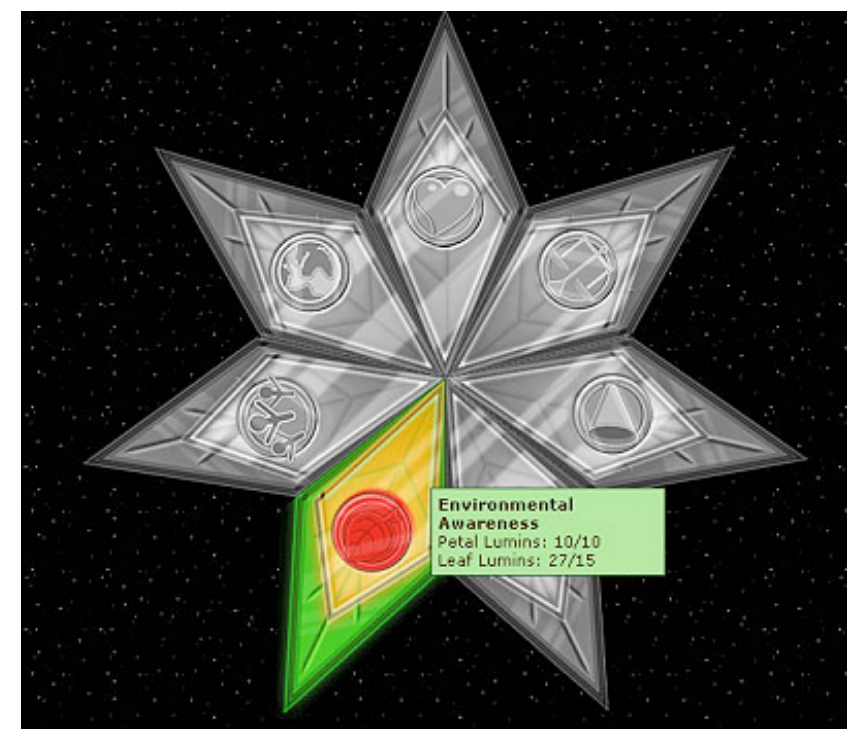

Figure 4: A luminated petal of a shard flower

Students were also interested in getting more cols to exchange for digital artefacts in their respective $Q$-packs, although some digital artefacts could be collected through mere exploration of the 3-D space. In Bernadette's words, cols were "like money..." in the $Q A$ MUVE. Many students shared that they would like to collect more cols to buy/exchange for digital artefacts to be kept in their respective $Q$-packs. According to some of them, cols were like currency for them to buy/exchange for things in this virtual environment.

While engaging in the various non-academic related tasks during the after school program, students still spent considerable amounts of time and effort in attempting the quests. The teachers' basic objective had been the students' engagement with the quests within the QA MUVE. For the students, their main motive for attending the after school program was not for the quests per se. For the students, it was a choice of engagement with quests or activities of their interest, including visiting their favourite websites, collecting digital artefacts, exploring the 3-D space for animated objects, to 
name a few. In essence, the students were engaged with both the mediating tool, namely the $Q A M U V E$, as well as other interesting and attractive websites available in the Internet.

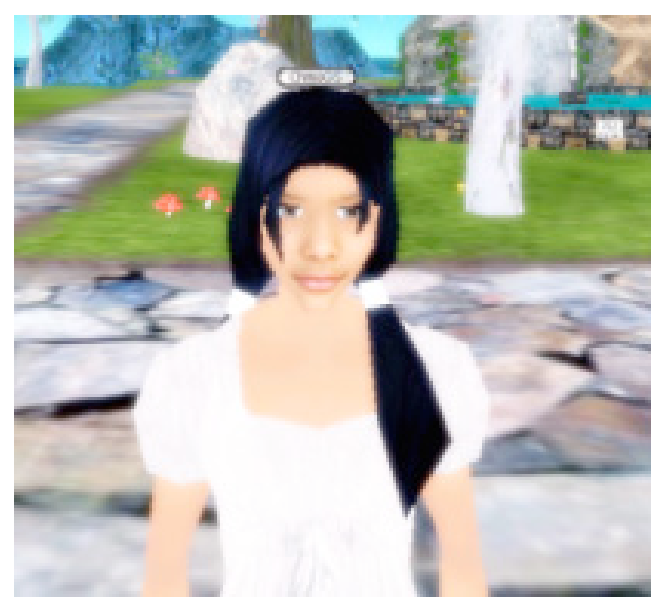

Figure 5a: A normal avatar

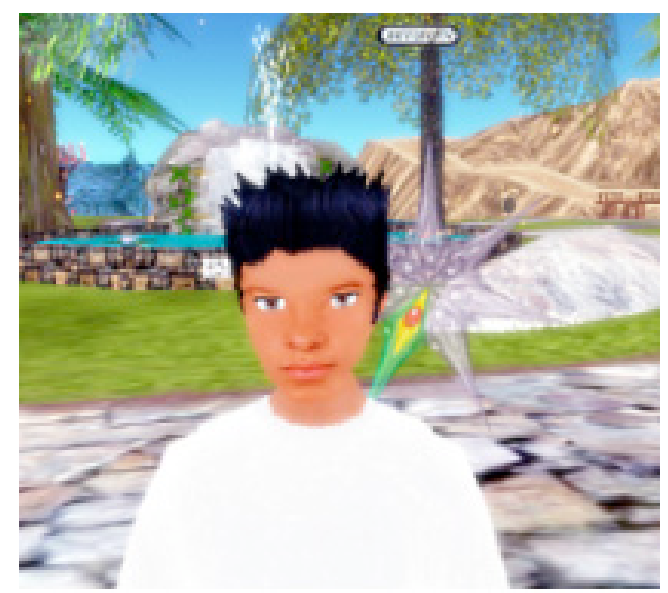

Figure 5b: Avatar with luminated shard flower on shoulder

As indicated above, the teachers not only reminded the students to attend the after school program, they also provided guidance and maintained classroom discipline while the students were working on their quests. Observations and interviews with students seemed to suggest that the QA MUVE was more than a tool to the students to complete their quests; it was also an online virtual environment with game like elements that attracted them. Nevertheless, teachers who assisted in conducting the after school program felt that students seemed to be better behaved, compared with their behaviour in their normal classes. One of the senior teachers even shared this observation with the rest of the teaching staff of the school during one of the staff meetings. She thought that students who often misbehaved and disengaged were observed to be very engaged during the after school program. This was also observed in earlier $Q A$ implementation in another primary school in Singapore where students were reported to be more engaged working within the QA MUVE (Lim, Nonis \& Hedberg, 2006).

\section{Students' academic performance}

This section compares results over three years for the $Q A$ after school program students and their counterparts in the average classes. Figure 6 shows that this group of $Q A$ after school program students was constantly under performing, compared with their peers who were in the average classes. There was also a common trend among their English and Mathematics scores. There was a decline in the examination scores for both the average students and the students in the $Q A$ after school program. The differences in the examination scores between the average students and the students in the $Q A$ after school program remained relatively constant over the years. When there was a dip in the mean examination score of the average students, there was also a corresponding drop of the same degree in the mean examination score of the students from the $Q A$ after school program. 


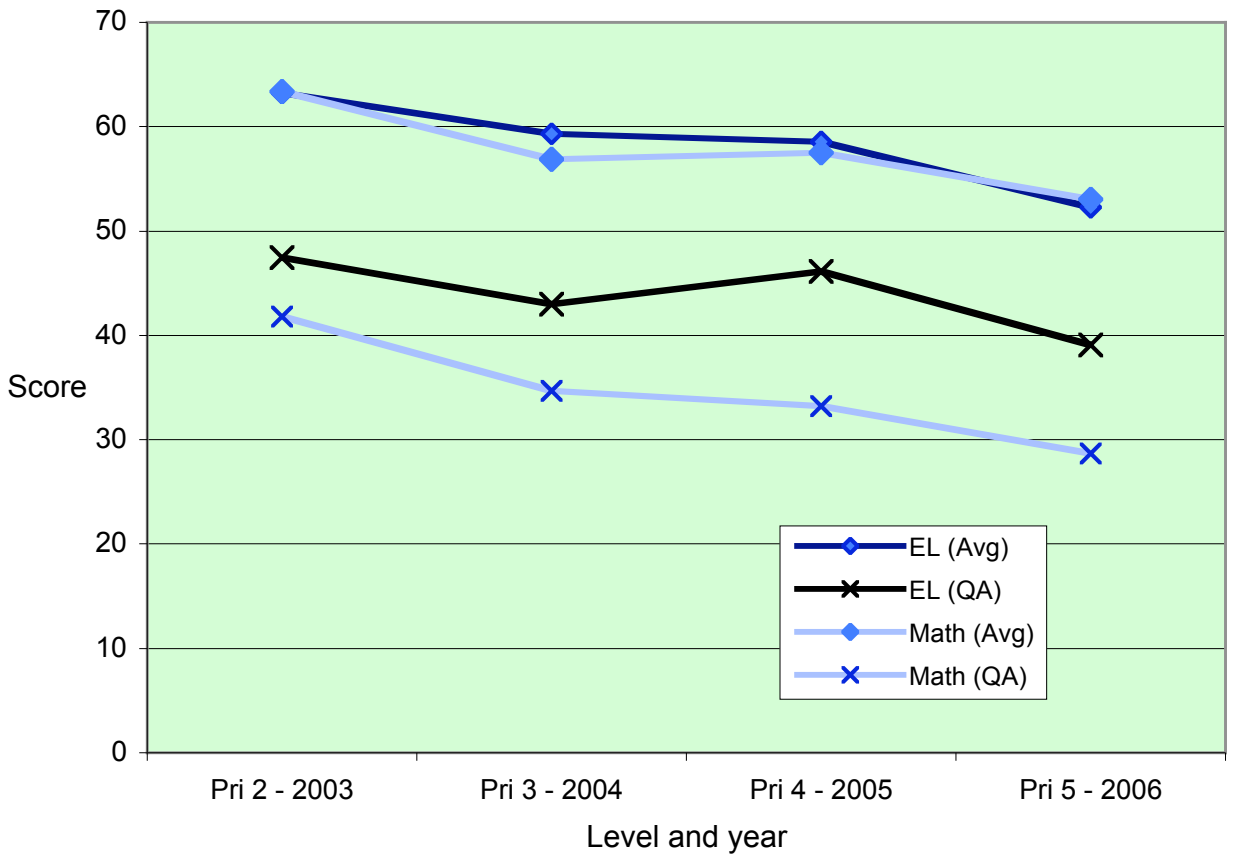

Figure 6: Mean English and Mathematics examination scores of average students and QA after school students (from Primary 2 to 5)

Thus no significant improvements or drops in academic performance were observed in the students of the $Q A$ after school program, compared with their counterparts in the average classes. However, this was not unexpected, as this group of students had not been doing well in their academic studies since Primary 2. In addition, the students were not found to be intrinsically engaged with the quests; their engagement was initiated mainly by the teacher who was conducting the after school program. Moreover, improvements in their academic performance would not be likely within such a relatively short timeframe (i.e. one year). Nevertheless, the students learned digital literacy skills from the program. ICT literacy would be a necessary skill for these students to function well in their future endeavours. All the students had gradually become more comfortable with the technologies, as compared to when they first joined the program.

\section{Implications}

\section{Quest Atlantis: The tool}

Students' engagement with the $Q A M U V E$ and the after school program was progressive. Time was spent on learning the virtual learning environment as well as the other related tools. The teachers provided the necessary training in terms of the functions, navigation within the virtual environment and generic computer competencies. Just in time teachings of specific computer skills were also provided during the sessions as and when certain content and technical skills were required. Students were exposed and learned technological skills and were very comfortable with the use of computers for their learning. In addition, time was also set aside for the 
students to get used to the more inquiry oriented type of learning which required more initiative and ownership from the students.

The students' main objective was play and fun with the computer and the 3-D MUVE. The teachers' objective was to get the students to be engaged in academic related activities, that is, the quests. The teachers and the students were constantly in a state of negotiation between the time spent in exploring the various aspects of the 3-D MUVE and the time spent in completing the quests assigned by the teacher; there was constant subtle negotiation between the students and the teachers. Frequent reminders were given to students who were supposed to be present at the after school program, especially during the earlier phases of the program. The students were repeatedly reminded of their roles as students, that is, to attend classes and engage in academically related tasks and activities as stipulated by the school and teachers. In addition, different tactics such as exchanges, influence, and coercion were used. As a form of exchange, students were allowed to visit their favourite websites before, after the after school program, and when they had finished their tasks. The teacher also tried to subtly influence the students by constantly focusing on the fun aspects of the QA virtual learning environment.

Although students used $Q A M U V E$ as a tool to gain access to the engaging elements (the fun and interactive elements found in the 3-D space as well as the lumins, cols, avatar, and the digital artefacts), these elements also became elements that the students were interested in, especially after the initial phase of the program. For the students, these elements within the QA MUVE were the elements that engaged them. Students used the computer (hardware) and the QA MUVE as a tool for gaining access to their objects. The engaging elements were in the forms of their favourite online Internet sites (games or blogs), the 3-D space in the QA MUVE, the lumins, cols, avatars, and digital artefacts.

\section{Quest Atlantis: The engaging elements}

The reward and recognition system within 3-D MUVE could be even better capitalised to re-engage and motivate students who were not too interested in their academic studies. This could only achieve its full potential if there was an awareness of its effectiveness and should be purposefully exploited by the teacher or personnel conducting such a program. Although it was the ultimate goal of many educators to have students who were intrinsically and naturally interested in the quest for knowledge and learned new things, effective use of the extrinsic form of rewards found within the virtual environment such as the lumins and cols in QA MUVE played a part in enticing the students to work for these digital rewards. It was not the reward itself that was important, but rather the students' belief about the consequences of their behaviour. The acquiring of these digital rewards allowed them to purchase digital artefacts, buy land, and change their avatar. For the design of the 3-D MUVE, the recognition, reward, avatar, digital artefacts, and 3-D environment seem to engage as well as motivate this group of at risk students to perform academic related tasks. In addition, students were also very interested in the 3-D environment. Many of the students spent considerable amount of time enjoying and engaging in it.

\section{The role of expectations}

With reference to the earlier discussions on the teachers' and the students' perspectives, it seems to suggest that the expectations and rules of the school (i.e. the 
community) played very critical roles towards the successful implementation of the $Q A$ after school program. Students were following the rules and expectations imposed on them in the after school program in order to engage in the quests assigned to them. Moreover, with reference to the teachers' perspective, the schedule of the after school program had inevitably afforded the attendance rate of the students. The expectations as set up by the community - teachers, parents and school - had a profound impact on the behaviour of these students, especially on their attendance during the initial phase and throughout the implementation. For instance, in this case, students had a choice of attending the after school program or staying away from it. A considerable number of them chose to come for the program as they knew clearly about the expectations of the community.

\section{The pivotal role of the teacher}

In addition to planning and negotiation with the school management for the implementation of such an after school program, teachers also played the role of the authoritative figures, as the enforcers of the rules set up by the school.

In this study, the teachers initiated, planned, and implemented the program. Content and pedagogical skills and knowledge were also used as tools to conduct and deliver the after school sessions. In addition to creating a conducive learning environment, the teachers also played the role of the Atlantian Council in grading the quests students submitted. The teacher-researcher and the teachers also acted as enforcers of the rules in terms of reminding them to attend the sessions as well as reprimanding those who were absent, and in terms of managing the students in a technologically enriched learning environment (Wong, 2000).

In this instance, teachers not only needed to be equipped with good content, pedagogical skills, and technological knowledge to use technology as a tool to engage the students, they also needed to work within the expectations and rules of the school.

\section{Differences between teachers and students}

Both the teachers and students were in a similar setting and used seemingly similar tools. However, they had similar as well as different objectives. The QA MUVE incorporating the 3-D interactive space, lumins, cols, avatar, and digital artefacts attracted the students as well as distracted them simultaneously from the completion of quests in the virtual environment.

Through this attempt to understand the students' behaviour within the after school program, this difference could be further capitalised with the use of the 3-D animated space and the digital reward system with the quests to better reconcile the differences between the teachers and the students. In other words, with this awareness, the 3-D interactive space and the digital rewards and artefacts could become more effective tools to engage students in academically related tasks.

Better understanding of the differences between how teachers and students perceive the use of technologies and in particular the 3-D MUVE, may inform better future practices in using technologies for teaching and learning in an after school context with academically at risk students. Teachers would be better able to plan and design learning activities in such a 3-D MUVE with respect to utilisation of the 3-D environment and different forms of extrinsic motivation (lumins, cols, avatar, and 
digital artefacts and collectable items). It is hence crucial to blend or incorporate the 3D play and fun elements with the quests; rather than to let the quests to be standalone, without the interactions with the 3-D environment.

Current research studies into intrinsic and extrinsic motivation also suggest rewards could be effectively used to motivate individuals, depending on how they are being used (Sansone \& Harachiewicz, 2000). In the past, some psychologists proposed that intrinsic motivation is better than extrinsic motivation. However, according to Lepper and Henderlong (2000), they are both equally important and can complement each other. "In the first place, not all activities we want children to undertake in school are naturally - or even can be made - intrinsically motivating. In many cases in the early stages of learning, the intrinsic value of a given activity may not even be apparent until the individual has acquired some minimal level of competence" (Lepper \& Henderlong, 2000, p. 294). They argue that in many cases, the judicious use of extrinsic incentives may be entirely appropriate, to encourage the level of initial interest in the task. If this is very low, the use of extrinsic rewards may have positive effects on later motivation. Hedi (2000), and Sansone and Smith (2000) also echo this view to shift the agenda towards finding the syntheses of intrinsic and extrinsic motivation that will engage students in learning skills they need for their futures. In addition, the use of extrinsic forms of motivation is even more relevant, given the pragmatic culture in Singapore where people tend to look for tangible forms of 'rewards' for activities they are engaged in.

\section{Limitations of this study}

There are three main limitations in this study. Firstly, this case study provides little basis for generalisation. Nevertheless, the context of the study is elaborated in detail to address this limitation - a rich content is provided. According to Stake $(1995$, p. 4), it may be useful to try to select cases that are typical or representative of other cases, but a sample of one or a sample of just a few is unlikely to be a strong representation of others. However, the primary intent of this case study is not to understand the other cases. The main purpose is to maximise what we can learn from this case study on how the use of a 3-D MUVE can be used to re-engage academically at risk students in school related work.

The second limitation is the teacher-researcher's assumptions and biases. Although there were several other teachers who were involved in this study, they were not as directly involved in the implementation. Recognising that his assumptions and biases can affect the data collection and its outcome, the teacher-researcher is open about his assumptions and biases. To overcome the disadvantage of having no third party in the data collection process, data analysis within each method, between methods, and within the case took place alongside data collection. Having ongoing analysis had two advantages. First, this helped to undo errors made in the field. Reflection notes after each session and transcriptions of the interviews were completed very promptly. This allowed time for the teacher-researcher to look through these notes and reflect upon how the data collection processes could be improved. Second, the ongoing analysis provided opportunities to refine the research methods to reflect a better understanding of the context. There were continuous efforts to triangulate the observations and the interviews conducted. However, at times, it was obvious that the interpretation of the teacher-researcher as well as that of the participants mediated all the data. To address this, the teacher-researcher constantly questioned his own assumptions. 
The third limitation is that students who are academically at risk represent a multidimensional phenomenon which could be contributed to by many factors. The engagement of students in the after school program may not be attributed solely to the ICT-enriched environment. Non-ICT activities such as orientation tasks, support by teachers, and the careful selection of authentic assignments (Lim, 2004) could have enhanced the engagement of the students. In addition, personal attention from the teachers could also further facilitate the engagement of these students. In short, the students' engagement might not be due exclusively to the ICT-enriched learning environment.

\section{Conclusion}

In this case of the after school program that has incorporated the use of a 3-D MUVE, the findings suggest that although both teachers and students co-exist in a common time and space, they have different objectives. With this better understanding of the different perspectives of the teachers' as well as the students, it provides a more in depth interpretation and hence insight into how technologies could be better utilised for the purpose of teaching and learning. This study also highlighted the importance of the context - the school, its expectations and rules - in which the innovation is situated.

The findings also suggest that ICT such as the QA MUVE could be used to engage and motivate students in learning academic related topics. However, this needs to be coupled with effective teachers having the necessary pedagogical and technological skills. The findings also suggest the possibility that an after school program could be introduced for students who have social and emotional behavioural problems, using quests that harness social responsibility, which can be developed within the QA MUVE.

\section{References}

Amory, A., Naicker, K., Vincent, J. \& Adams, C. (1999). The use of computer games as an instructional tool: Identification of appropriate game types and game elements. British Journal of Educational Technology, 30, 311-321.

Barab, S. A., Thomas, M., Dodge, T., Carteaux, R. \& Tuzun, H. (2005). Making learning fun: Quest Atlantis, a game with guns. Educational Technology Research and Development, 53, 86-107.

Beck, E. L. (1999). Prevention and intervention programming: Lessons from an after-school program. The Urban Review, 31, 107-124.

Chee, Y. S. (2006). Experientially-grounded learning in multi-user virtual worlds. In M. S. Khine (Ed.), Teaching with technology: Strategies for engaging learners (pp. 295-322). Singapore: Pearson, Prentice Hall.

Cole, M. (1998). Cultural psychology: A once and future discipline. Cambridge MA: Harvard University Press.

Copper, H., Valentine, J. C., Nye, B. \& Lindsay, J. J. (1999). Relationships between five afterschool activities and academic achievement. Journal of Educational Psychology, 91, 369-378.

Cosden, M., Morrison. G., Gutierrez. L \& Brown, M. (2004). The effects of homework programs and after-school activities on school success. Theory Into Practice, 43, 221-226.

Dede, C., Clarke, J., Ketelhut, D. J., Nelson, B. \& Bowman, C. (2005). Fostering motivation, learning, and transfer in multi-user virtual environments. Paper presented at the American Educational Research Association Conference, Montreal, Canada. [verified 7 Oct 2008] http:/ / muve.gse.harvard.edu/rivercityproject/documents/Dede_Games_Symposium_AERA_2005.pdf 
Dickey, M. (2005). Engaging by design: How engagement strategies in popular computer and video games can inform instructional design. Educational Technology Research and Development, 53, 67-83.

Gee, J. P. (2003). What video games have to teach us about learning and literacy. Fifth Avenue, NY: First Palgrave Macmillan.

Gee, J. P. (2004). Situated language and learning: A critique of traditional schooling. NY: Routledge.

Girod, M., Martineau, J. \& Zhao, Y. (2004). After-school computer clubhouses and at-risk teens. American Secondary Education, 32, 63-76. [verified 7 Oct 2008] http: / / zhao.educ.msu.edu / vita/ publications / 7-After-school\%20computer\%20clubhouses.pdf

Hedi, S. (2000). An interest researcher's perspective: The effects of extrinsic and intrinsic factors on motivation. In C. Sansone \& J. Harachiewicz (Eds.), Intrinsic and extrinsic motivation - the search for optimal motivation and performance (pp. 309-339). London: Academic Press.

Herrington, J., Oliver, R. \& Reeves, T. C. (2003). Patterns of engagement in authentic online learning environments. Australian Journal of Educational Technology, 19(1), 59-71. http: / / www.ascilite.org.au/ajet/ajet19/herrington.html

Jenkins, H., Klopfer, E., Squire, K. \& Tan, P. (2003). Entering the education arcade. ACM Computers in Entertainment, 1, 1-10.

Lepper, M. \& Henderlong, J. (2000). Turning "play" into "work" and "work" into "play": 25 years of research on intrinsic versus extrinsic motivation. In C. Sansone \& J. Harachiewicz (Eds.), Intrinsic and extrinsic motivation: The search for optimal motivation and performance (pp. 257-307). London: Academic Press.

Lim, C. P. (2004). Engaging learners in online learning environments. TechTrends, 48(4), 16-23.

Lim, C. P., Nonis, D. \& Hedberg, J. (2006). Gaming in a 3-D multi-user virtual environment (MUVE): Engaging students in science lessons. British Journal of Educational Technology, 37(2), 211-231.

Maehr, M. L. \& Anderman, E. (1993). Reinventing schools for early adolescents: Emphasizing task goals. Elementary School Journal, 93, 593-610.

Malone, T. W. \& Lepper, M. (1987). Making learning fun: Taxonomy of intrinsic motivations of learning. In R. E. Snow \& M. J. Farr (Eds.), Aptitude, learning, and instruction: Vol 3. Conative and affective process analysis (p. 223-253). Hillsdale, NJ: Lawrence Erlbaum.

Margolis, H. \& McCabe, P. (2006). Improving self-efficacy and motivation: What to do, what to say. Intervention in School and Clinic, 41, 218-227.

Mukhopadhaya, P. (2003). Trends in income disparity and equality enhancing education policies in the development stages of Singapore. International Journal of Educational Development, 23, $37-56$.

NWREL (Northwest Regional Educational Laboratory) (1997). Inquiry strategies for science and mathematics learning: It's just good teaching. Northwest Regional Educational Laboratory. [verified 7 Oct 2008] http:/ / www.nwrel.org/msec/images/resources/justgood/06.97.pdf

Quah, M. L, Sharpe, P., Lim, S. E. \& Heng, M. A. (1999). In J. Tan, S. Gopinathan \& Ho W. K. (Eds.), Education in Singapore - a book of readings (pp.319-342). Prentice Hall: Singapore.

Roeser, R. W., Strobel, K. R. \& Quihuis, G. (2002). Studying early adolescents' academic motivation, social-emotional functioning, and engagement in learning: Variable- and personcentered approaches. Anxiety, Stress and Coping, 14, 345-368. 
Sansone, C. \& Harachiewicz, J. (2000). Controversies and new directions: Is it déjà vu all over again? In C. Sansone \& J. Harachiewicz (Eds.), Intrinsic and extrinsic motivation: The search for optimal motivation and performance (pp. 445-453). London: Academic Press.

Sansone, C. \& Smith, J. (2000). Interest and self-regulation: The relation between having to and wanting to. In C. Sansone \& J. Harachiewicz (Eds.), Intrinsic and extrinsic motivation: The search for optimal motivation and performance (pp. 341-371). London: Academic Press.

Stake, R. E. (1994). Case studies. In N. K. Denzin \& Y. S. Lincoln (Eds.), Handbook of qualitative research (pp. 236-247). Thousand Oaks, California: SAGE Publications.

Stake, R. E. (1995). The art of case study research. Thousand Oaks, California: SAGE Publications.

Seifert, T. \& O'Keefe, B. (2001). The relationship of work avoidance and learning goals to perceived competency, externality and meaning. British Journal of Educational Psychology, 71, 81-92.

Urdan, T. C., Midgley, C. \& Anderman, E. M. (1998). The role of classroom goal structure in students' use of self-handicapping. American Educational Research Journal, 35, 101-122.

Wong, P. (2000). Managing IT classrooms. In M. D. Willams (Ed.), Integrating technology into teaching and learning: Concept and applications - an Asia-Pacific perspective (pp. 121-139). Singapore: Prentice Hall.

Tay Lee Yong is the Head of Research and Information Communication Technology in his school. He obtained his PhD in Education from Edith Cowan University, Western Australia. Email: tay_lee_yong@moe.edu.sg

Lim Cher Ping is an Associate Professor at the School of Education, Edith Cowan University. He is currently Director of the Asia-Pacific Centre of Excellence for Teacher Education and Innovations [http:/ / www.education.ecu.edu.au/research/apcetei/], and International Partnership Director at Edith Cowan University, Western Australia. Email: c.lim@ecu.edu.au 